notes de lecture

\title{
Researching Private Supplementary Tutoring: Methodological Lessons from Diverse Cultures
}

Mark Bray, Ora Kwo, Boris Jokić (ed), Comparative Education Research Centre (CERC)/Springer, octobre 2015, 292 p.

\section{Roger-François Gauthier}

\section{(2)enEdition Journals}

Édition électronique

URL : https://journals.openedition.org/ries/5591

DOI : 10.4000/ries.5591

ISSN : 2261-4265

Éditeur

France Education international

Édition imprimée

Date de publication : 1 décembre 2016

Pagination : $35-36$

ISBN : 978-2-85420-612-8

ISSN : $1254-4590$

Référence électronique

Roger-François Gauthier, «Researching Private Supplementary Tutoring: Methodological Lessons from Diverse Cultures », Revue internationale d'éducation de Sèvres [En ligne], 73 | décembre 2016, mis en ligne le 01 décembre 2016, consulté le 03 juillet 2021. URL : http://journals.openedition.org/ries/ 5591 ; DOI : https://doi.org/10.4000/ries.5591

Ce document a été généré automatiquement le 3 juillet 2021

(c) Tous droits réservés 


\title{
Researching Private Supplementary Tutoring: Methodological Lessons from Diverse Cultures
}

\author{
Mark Bray, Ora Kwo, Boris Jokić (ed), Comparative Education Research
}

Centre (CERC)/Springer, octobre 2015, 292 p.

\section{Roger-François Gauthier}

1 Le titre de ce livre ne se réfère pas, comme dans d'autres publications de Mark Bray, à l'éducation de l'ombre, mais à un concept plus vague et couvrant le soutien scolaire privé, dirait-on en français. Cet ouvrage propose des monographies sur une dizaine de pays, de tous les continents, tout en proposant quelques chapitres transversaux qui portent autant sur les recherches attendues que sur celles dont sont déjà présentés les résultats. Trois chapitres se penchent sur la question des instruments pour les études quantitatives, à partir d'études effectuées en Malaisie, en Géorgie et en Chine. Puis des études plus qualitatives, ou mixtes, sont consacrées notamment à la situation en Iran, à Hong-Kong, en Jamaïque, au Cambodge et aux Maldives.

2 En effet, ce qui est intéressant, c'est que cette question au début anecdotique, qui semblait réservée à certains pays d'Asie de l'Est, devient une des questions majeures posées au futur de l'éducation dans le monde.

3 Les auteurs font d'abord remarquer à quel point le développement du private tutoring change fondamentalement un paysage scolaire : les familles mobilisent des ressources financières, quand elles le peuvent, le temps de la vie des élèves se trouve chamboulé, ainsi que les revenus de certains enseignants, spécifiques ou les mêmes que ceux du système public, mais aussi du coup la carte de l'embauche dans les métiers de l'enseignement et jusqu'à la configuration des savoirs.

4 Au-delà de cet impact assez général, malgré des variantes, les auteurs font remarquer qu'aujourd'hui ce private tutoring se retrouve au sein de cultures scolaires très différentes, comme l'Iran, la Chine ou la Jamaïque. Cela dit, il faut s'accorder sur la 
question de savoir si on reconnaît bien le même objet sous des intitulés très différents : private tuition, private tutoring, coaching, extra-lessons, soutien scolaire, parapedia (Grèce). Or ce que recouvrent ces activités, ce sont des réalités évolutives et mouvantes. En ce qui concerne les rapports entre elles et "le reste ", c'est-à-dire le système public ou privé mais correspondant à l'école de référence, le terme d' "éducation de l'ombre ", par exemple, semble de moins en moins adapté pour désigner une éducation qui se montre à la lumière et qui est de moins en moins l'ombre (au sens de ce qui copie et se conforme) à l'école de référence.

En ce qui concerne l'organisation matérielle des choses, on a aussi bien des rassemblements d'élèves par effectifs réduits, qu'au contraire de très grandes classes, ou bien des enseignements virtuels pouvant le cas échéant être totalement délocalisés et bénéficier à des enfants de pays différents.

Sont enseignés dans ces officines des savoirs académiques renforcés, essentiellement dans les pays qui ont des systèmes d'examens exigeants, mais aussi ailleurs ou aux mêmes endroits, plutôt la musique ou l'éducation religieuse, pour permettre aux enfants de développer leur capital social. L'estime de soi et l'apprendre à apprendre deviennent, étonnamment, objet d'enseignement de cours qu'on pensait définitivement tournés vers ce qui était valorisé aux examens et facile à mesurer.

7 S'agissant des formes institutionnelles et économiques, on trouve du soutien privé en maternelle, mais aussi des écoles offrant un « package » fait à la fois d'école de référence et de cours de soutien, ou seulement le soutien. Au plan sociologique, on peut trouver dans la même société des écoles privées de soutien pour pauvres et d'autres s'adressant à une clientèle aisée.

8 Les auteurs montrent aussi qu'à l'exception partielle des pays scandinaves, où, en général, les questions posées ailleurs au tutoring privé trouvent réponse dans le cadre normal de l'école publique, tous les pays, toutes les cultures éducatives du monde semblent touchées. Certes il est rappelé que les pays de tradition confucianiste ont proposé un terrain favorable, en raison de l'importance attachée à la scolarisation, mais on peut dire qu'aujourd'hui, tous les développements inégalitaires, au plan scolaire, qui touchent les sociétés ou la société internationale, entraînent le développement d'une surenchère propice au soutien scolaire privé : c'est fortement le cas en Afrique en raison de la qualité du système public, mais c'est aussi le cas dans des familles asiatiques, par exemple, si internationalisées que la compétition entre les enfants est construite dans ce contexte.

9 Les auteurs insistent sur toutes les recherches, qualitatives et quantitatives, qui seraient nécessaires pour mieux interroger ce phénomène, dont l'ampleur se développe, pour interroger l'économie du système, son impact sur l'école de références, ses conséquences curriculaires, son impact sociétal, tout en insistant sur les difficultés d'approche selon les pays, les cultures, la volonté politique de cacher ou non la situation, ou la disponibilité de données. Ils nous invitent à comprendre que si le développement de la scolarisation a été la grande affaire du $\mathrm{XX}^{\mathrm{e}}$ siècle, ce siècle-ci montre que cette école du soutien scolaire privé a un véritable projet d'usurpation de l'enseignement pour tous. Partout, ou presque, et sous cent visages. 


\section{AUTEUR}

\section{ROGER-FRANÇOIS GAUTHIER}

Roger-François Gauthier, inspecteur général de l'administration de l'éducation nationale et de la recherche, est professeur associé à l'Université Paris-Descartes (France) et membre du Conseil supérieur des programmes. Ses travaux, au sein des institutions françaises et comme chercheur ou consultant auprès de plusieurs organisations internationales (Unesco, Organisation internationale de la Francophonie : OIF) relèvent soit d'études spécifiques à un pays soit des comparaisons internationales. Ils portent notamment sur les contenus d'enseignement et les politiques curriculaires, sujets à propos desquels il a écrit plusieurs ouvrages. Courriel : rogerfrancois.gauthier@education.gouv.fr 